\title{
Estruturas familiares na Prefeitura Municipal de Curitiba: uma prosopografia do secretariado de primeiro escalão do governo de Rafael Greca de Macedo no início de 2017
}

\author{
Fernando Marcelino Pereira ${ }^{1}$ \\ Marcus Roberto de Oliveira²
}

\begin{abstract}
RESUMO: O presente trabalho consiste num sistemático estudo acerca do secretariado de primeiro escalão da administração de Rafael Greca de Macedo frente à Prefeitura Municipal de Curitiba no exórdio do ano de 2017. As trajetórias sociais, políticas e profissionais dos secretários do atual Executivo curitibano foram identificadas e analisadas por meio de métodos prosopográficos. Os resultados obtidos indicam que as relações sociais de base familiar forneceram condições e critérios de recrutamento na referida gestão.
\end{abstract}

Palavras-chave: Secretariado do governo municipal de Rafael Greca de Macedo em 2017. Política Paranaense. Redes de Parentesco.

\section{Family structures in the City Hall of Curitiba: a prosopography of the first secretariat of the government of Rafael Greca de Macedo in early 2017}

\begin{abstract}
The present work consists of a systematic study about the first secretariat of the administration of Rafael Greca de Macedo in front of the Municipality of Curitiba in the exordium of the year 2017. The social, political and professional trajectories of the secretaries of the current executive in Curitiba were identified and analyzed By means of prosopographic methods. The results obtained indicate that the family-based social relations provided conditions and recruitment criteria in said management.
\end{abstract}

Keywords: Secretariat of the municipal government of Rafael Greca de Macedo in 2017. Politics Paranaense. Kinship Networks.

- Enviado em 01/05/2017

- Aprovado em 17/05/2017

\begin{abstract}
1 Bacharel em Relações Internacionais pelo Centro Universitário Curitiba (UNICURITIBA), mestre em Ciência Política e doutorando em Sociologia pela Universidade Federal do Paraná (UFPR). Uma versão preliminar desse texto foi apresentada no VIII Seminário Nacional de Sociologia e Política realizado de 17 a 19 de maio de 2017 na UFPR. E-mail: fernandomarcelinopereira@gmail.com
\end{abstract}

2 Bacharel em Ciências Sociais, mestre em Sociologia Política e doutorando em Sociologia pela Universidade Federal do Paraná (UFPR). Uma versão preliminar desse texto foi apresentada no VIII Seminário Nacional de Sociologia e Política realizado de 17 a 19 de maio de 2017 na UFPR E-mail: mr_olivei@yahoo.com.br 


\section{INTRODUÇÃO}

Na vida política, quando chamamos atenção para importância das relações familiares nas situações tradicionais de exercício do poder (FAORO, 2001), "a família é certamente uma [...] 'ilusão bem fundamentada' já que, produzida e reproduzida com a garantia do Estado, ela sempre recebe do Estado os meios de existir e de subsistir" (BOURDIEU, 1996, p. 135). Nessa lógica, a disputa eleitoral pela Prefeitura de Curitiba em 2016 representou bem como as estruturas familiares agem na política.

Os cinco principais candidatos do pleito curitibano de 2016 vieram de famílias tradicionais da política: Rafael Greca de Macedo pelo Partido da Mobilização Nacional (PMN), Gustavo Fruet pelo Partido Democrático Trabalhista (PDT), Requião Filho pelo Partido do Movimento Democrático Brasileiro (PMDB), Ney Leprevost pelo Partido Social Democrático (PSD) e Maria Victória Barros pelo Partido Progressista (PP); todos são herdeiros diretos e indiretos das velhas oligarquias que dominam o Paraná. A vitória de Greca de Macedo sobre Leprevost no segundo turno, inclusive, apontou para o retorno da classe dominante mais tradicional ao comando da cidade (OLIVEIRA, 2012).

A ascendência da família Macedo, tem como berço a Monarquia Portuguesa do século XI, com Gonçalo Annes Borges, décimo primeiro avô de Simão Borges de Cerqueira, pai de Maria de Cerqueira Leme, que se casou em Itú com o Fidalgo Duarte da Távora Gambôa, português natural de Alhos Verdes. Tiveram uma filha chamada Catharina de Macedo Baldraga, a qual se matrimoniou com João Corrêa de Fonseca, sendo este o tronco da linhagem Macedo no Paraná. João Corrêa e Catharina tiveram vários filhos, entre eles, Maria Corrêa de Macedo que se uniu a Manoel Ribeiro Callado, deixando descendência de seis filhos, dentre eles, Manoel Ribeiro de Macedo. (MACEDO; BACELLAR, 1998).

A descendência de Manoel Ribeiro de Macedo passou a ocupar os espaços sociais de decisão e prestígio diretamente vinculados ao poder político (Executivo, Legislativo e Judiciário) e à burocracia pública. É possível identificar seus ramos familiares na Interventoria, no Governo do Estado, na Polícia Estadual e Federal, no Tribunal de Justiça do Paraná (TJ-PR), no Tribunal de 
Alçada do Paraná (TAPR), no Tribunal de Contas do Estado do Paraná (TCE-PR), na Assembleia Legislativa do Paraná (ALEP), em prefeituras de diversos municípios, na reitoria da UFPR, nas secretarias do Estado, no magistério público, no antigo Tesouro do Estado, na indústria e no comércio. Em relação ao campo comercial, nos 108 anos de Associação Comercial do Paraná (ACP), 37 foram presididos por pessoas descendentes ou ligados diretamente à família de Manoel Ribeiro de Macedo (Idem).

Aqueles que não possuíam vínculos matrimoniais com famílias tradicionais pertencentes à elite, tratavam de estabelecê-lo, assim a sua filha Anna Rosa de Macedo matrimoniou-se com a importante família do Tenente Coronel James Pinto de Azevedo Portugal, que vinha a ser filho do Coronel Francisco Pinto de Azevedo Portugal e neto de Diogo Pinto de Azevedo Portugal (conquistador militar a serviço da Coroa Portuguesa). Desse tronco que reúne a família Macedo e a Azevedo Portugal iniciou a linhagem mais tradicional do sistema judicial paranaense, constituindo um clã de juristas composto, direta ou indiretamente, por sete famílias: Macedo Portugal, Azevedo Portugal, Rotoli de Macedo, Riquelme de Macedo, Pereira de Macedo, Marés de Souza e Sotto Maior (PEREIRA, 2016).

Rafael Valdomiro Greca de Macedo nasceu em Curitiba em 17 de março de 1956. Filho da professora Terezinha Greca de Macedo e de Eurico Dacheux de Macedo, (engenheiro do Departamento de Estradas e Rodagem (DER) do Paraná), Greca de Macedo é casado com a jornalista Margarita Sansone (Idem).

Em sua trajetória escolar, Greca de Macedo formou-se em Economia pela Fundação de Estudos Sociais do Paraná (FESP) em 1977, e em Engenharia Civil, com especialização em Urbanismo, pela Universidade Federal do Paraná (UFPR) em 1978. (Ibidem)

Lançado pelo então prefeito Jaime Lerner ${ }^{3}$ (Aliança Renovadora Nacional - ARENA e PDT) na década de 80, Greca de Macedo foi vereador e prefeito (com o primeiro mandato entre 1993-

\footnotetext{
3 “Jaime Lerner, nascido em Curitiba em 17 de dezembro de 1937 é arquiteto e planejador urbano, formado pela Escola de Arquitetura da Universidade Federal do Paraná em 1964. Responsável pela criação e estruturação do Instituto de Planejamento Urbano de Curitiba (Ippuc) em 1965, participou do desenvolvimento do Plano Diretor de Curitiba que resultou no processo de transformação física, econômica e cultural da cidade. Foi prefeito de Curitiba em três mandatos: nos períodos de 1971/75, de 1979/83 e de 1989/92". Disponível em http://www.casacivil.pr.gov.br/modules/conteudo/conteudo.php?conteudo=91; acesso em 21/04/2017.
} 
1996) pelo PDT. Para além da esfera municipal, também foi: deputado federal (o mais votado do Estado) em 1998, ministro de Estado do Esporte e Turismo no segundo governo do presidente Fernando Henrique Cardoso (do Partido da Social Democracia Brasileira - PSDB) de 1999 a 2000 (deixando o cargo após polêmicos episódios acerca da comemoração dos 500 anos do Brasil ${ }^{4}$ ) e deputado estadual em 2002. Os três cargos pelo antigo Partido da Frente Liberal (PFL) (Ibidem).

Um pouco mais tarde deixou o grupo lernista e tornou-se aliado de Roberto Requião ${ }^{5}$ (PMDB) (que até então, era um tradicional adversário político do atual prefeito eleito), filiando-se ao mesmo partido. Já filiado ao PMDB, em 2006 buscou a reeleição, mas apenas integrou o quadro peemedebista de suplentes do legislativo estadual paranaense. Em 2007 assumiu a presidência da Companhia de Habitação do Paraná (COHAPAR) por indicação do então governador Roberto Requião (Ibidem).

Em julho de 2008 o Ministério Público do Paraná (MP-PR) abriu procedimento investigatório para apurar as denúncias de que a COHAPAR gastou, entre fevereiro de 2007 e abril de 2008 , mais de $\mathrm{R} \$ \mathbf{2 7 0 0 0 , 0 0}$ (vinte e sete mil reais) com despesas de alimentação pessoal de seu presidente. Os gastos incluem refeições em restaurantes de luxo em Curitiba, como o llle de France (especializado em cozinha internacional de alto padrão), o restaurante do Graciosa Country Club, Anarco Empório Restaurante, Ka Kiun Kim Cozinha Oriental, Estrela da Terra, La Pasta Gialla, Karbonel Frutos do Mar, Churrascaria Alto da Glória, Alma Lusa, Ponte Vecchio, Churrascaria do Erwin, entre outros ${ }^{6}$. Nos restaurantes especializados em comida japonesa, tailandesa e chinesa, foram despendidos mais de $\mathrm{R} \$ 3200,00$ (três mil e duzentos reais). Em quatro jantares no

4 Disponível em http://www.dgabc.com.br/Noticia/257838/greca-sera-processado-por-falhas-da-nau-capitanea; acesso em 24/04/2017.

5 "Roberto Requião de Mello e Silva nasceu em 5 de março de 1941, em Curitiba (Paraná), filho do médico e exprefeito de Curitiba Wallace Thadeu de Mello e Silva e Lucy Requião de Mello e Silva. Casado com Maristela Quarenghi de Mello e Silva, pai de Maurício Thadeu e Roberta. Formado em Direito pela Universidade Federal do Paraná e em Jornalismo pela Pontifícia Universidade Católica do Paraná, cursou Urbanismo pela Fundação Getúlio Vargas. [...] Sempre pelo PMDB, foi Deputado Estadual (1983-85), Prefeito de Curitiba (1986-89), Secretário do Desenvolvimento Urbano do Estado do Paraná (1989-90), Governador do Paraná (1991-95), Senador da República (1995-2002), Governador do Paraná (2003-2007) e eleito novamente Governador (2007-2011). Em uma nova disputa por uma vaga no Senado Federal, foi eleito para um mandato de oito anos, cargo que ocupa atualmente". Disponível em http://www.robertorequiao.com.br/trajetoria-2/; acesso em 23/04/2017.

6 Disponível em http://www.bemparana.com.br/noticia/73751/mp-investiga-jantares-de-greca-pagos-pelacohapar; acesso em 24/04/2017. 
restaurante Ille de France teriam sido gastos mais de $\mathrm{R} \$ 1037,00$ (mil e trinta e sete reais). As carnes nobres eram as mais apreciadas por Greca de Macedo. Somente as churrascarias de Curitiba já tiveram lucro superior a $\mathrm{R} \$ 2400,00$ (dois mil e quatrocentos reais) com a estatal ${ }^{7}$.

Reafirmando grande poder e influência de uma das mais antigas oligarquias do Paraná, Rafael Greca de Macedo retorna à frente Prefeitura Municipal de Curitiba vencendo as eleições de 2016. Assim, numa de suas primeiras iniciativas, formou um secretariado que reflete sua tradicional trajetória política em inúmeros aspectos.

\section{O SECRETARIADO DE RAFAEL GRECA DE MACEDO EM 2017}

Apesar de entoar durante a campanha o discurso de "gestão técnica", o anúncio do primeiro escalão do segundo governo municipal Greca de Macedo chama a atenção por ter pelo menos dez nomes próximos ao atual governador Beto Richa (PSDB).

O destaque de tal vínculo aponta primeiramente para Marcelo Richa, filho do mandatário estadual e escolhido pelo prefeito para Secretaria Municipal de Esportes. Além do rebento, a presidência da Fundação de Assistência Social (FAS) ficou com Larissa Marsolik Tissot, assessora da atual primeira dama Fernanda Vieira Richa.

Na sequência da aliança Greca de Macedo/Richa, Luiz Jamur (secretário de Urbanismo da Prefeitura de Curitiba quando Beto Richa era prefeito, também secretário municipal na gestão "tampão" de Luciano Ducci ${ }^{8}$ do Partido Socialista Brasileiro (PSB) e diretor geral da Paraná Edificações na hodierna administração estadual) foi escolhido como secretário de Governo de Greca, Vitor Puppi (diretor geral da Secretaria Estadual de Fazenda de Richa) vai para Secretaria de Finanças e Marcelo Cattani, (ex-secretário estadual de Comunicação de Richa) foi escolhido para cargo equivalente na prefeitura de Greca de Macedo.

\footnotetext{
7 Disponível em http://www.bemparana.com.br/noticia/107221/mp-denunciara-greca-por-farra-na-cohapar; acesso em 23/04/2017.

${ }^{8}$ Com a eleição de Beto Richa ao governo do Estado em 2010, Luciano Ducci (então vice-prefeito de Curitiba) assume o cargo de prefeito da capital paranaense até o final de 2012. Maiores informações estão disponíveis em http://www.cmc.pr.gov.br/ass det.php?not=14847\#\&panel1-1; acesso em 23/04/2017.
} 
E não para por aí, o economista Jose Antonio Andreguetto, que foi secretário municipal de Meio Ambiente na gestão de Richa na prefeitura, agora presidirá a Urbanização de Curitiba S/A (URBS), José Lupion Neto (ex-coordenador da Coordenadoria Estadual de Proteção e Defesa do Consumidor / PROCON-PR) estará à frente da Companhia de Habitação Popular de Curitiba (COHAB), Luiz Dâmaso Guzzi, que já foi presidente da Central de Abastecimento do Paraná S/A (CEASA-PR), será o novo secretário municipal de Abastecimento e Agricultura e Vanessa Volpi, que foi assessora jurídica da campanha de Greca de Macedo e era funcionária comissionada na Casa Civil na gestão estadual de Richa, agora ocupará a Procuradoria Geral do Município (PGM) de Curitiba 9

Além da proximidade em relação ao grupo político do governador Beto Richa, o secretariado do segundo governo municipal de Greca de Macedo também é composto diversos membros de famílias tradicionais políticas (OLIVEIRA, 2012). Dos 25 nomes anunciados para o primeiro escalão da gestão municipal, pelo menos 10 são de famílias políticas mais ou menos tradicionais. Todos em postos importantes da "nova" Prefeitura de Greca de Macedo. Desses, dois são netos de ex-governadores (Lupion e Pimentel), um é filho do governador atual (Richa), um é filho de prefeito (Jamur), uma é esposa de ex-deputado (Pizzato), dois são filhos de ex-vereadores (Zanin e Costa) e três são membros de famílias presentes no TJ-PR, no TCE-PR, no MP-PR, além de cartórios e escritórios de advocacia (Turra, Volpi e Andreguetto).

As referidas credenciais das famílias em questão serão analisadas e detalhadas por meio de métodos prosopográficos. O termo "prosopografia" pode ser compreendido como "a investigação das características comuns de um grupo de atores na história por meio de um estudo coletivo de suas vidas", e sua finalidade "é dar sentido à ação política", aclarar "a mudança ideológica ou cultural, identificar a realidade social", assim como delinear e "analisar com precisão a estrutura da sociedade e o grau e a natureza dos movimentos em seu interior" (STONE, 2011, p. 115-116). Tal método é sugerido devido ao fato de apresentar instrumentos que podem detalhar grupos sociais tanto nas suas composições, quanto nas suas atuações públicas.

9 Disponível em http://www.poderjuridico.com.br/aliados-de-richa-abocanham-10-dos-24-cargos-de-primeiroescalao-de-greca/; acesso em 20/04/2017. 
Nos próximos tópicos, buscaremos levantar indicadores prosopográficos de cada um dos secretários indicados por Greca de Macedo, com destaque às trajetórias políticas e sociais de suas respectivas famílias.

\section{EDUARDO PIMENTEL SLAVIERO}

O Secretário de Infraestrutura e vice-prefeito de Rafael Greca de Macedo é Eduardo Pimentel Slaviero. Nascido em 21 de setembro de 1984 em Curitiba. Filou-se ao PSDB em 2009 e passou a ser diretor de marketing da Fundação Cultural de Curitiba (FCC) do segundo governo municipal de Beto Richa (2009-2012) (PEREIRA, 2016).

Foi candidato em 2010 para deputado estadual, não obtendo sucesso. A disputa nas eleições de 2014 era certeira, entretanto houve a desistência por parte de Eduardo, que assumiu a subchefia da Casa Civil do Paraná e depois se tornou assessor especial do governador. Eduardo é casado com a publicitária Paula Mocellin, filha de Marcos Mocellin e Stella Antunes Mocellin e neta do pediatra Irineu Antunes Filho. O casamento foi em 2010 no Salão Azul do Clube Curitibano (Idem).

Os avôs de Eduardo são Rubens e Ruth Slavieiro por parte de pai e Paulo e Ivone Pimentel por parte de mãe. Paulo Pimentel foi governador do Paraná entre 1966 e 1971 pela ARENA e, por sua vez, era genro de João Lunardelli, dono das maiores proprietárias de terras e glebas no Norte do Paraná e irmão de Geremia Lunardelli, o "rei do café" (Ibidem).

Na sequência da linhagem, os pais de Eduardo são Claudio Gomes Slavieiro e Isabel Lunardelli Pimentel. Seu pai é natural de Irati e empresário nos ramos agropecuário, automotivo, reflorestamento e construção civil, além de ex-presidente da ACP, diretor da Federação das Indústrias do Paraná (FIEP) e conselheiro do Sindicato Nacional das Indústrias de Cimento (SNIC) (OLIVEIRA, 2012).

Claudio Gomes Slaviero também já foi suplente do Conselho de Administração do Banco Regional de Desenvolvimento do Extremo Sul (BRDE). Nesse ramo genealógico, a família Gomes é 
uma das principais acionistas da fábrica de cimentos Itambé, cujo controle acionário está nas mãos de famílias paranaenses (62\% divididos entre os Slaviero, os Gomes e os Araújo). O Coronel Emílio Batista Gomes foi o primeiro prefeito do município de Irati-PR, em 1907. Um dos netos dele foi o governador do Paraná, Emílio Hoffmann Gomes, eleito pela Assembleia Legislativa em 1973 e governador até 1975 (Idem).

Eduardo Pimentel Slaviero tem um irmão e uma irmã. Daniel Pimentel Slaviero, que é o atual presidente da Associação Brasileira de Emissoras de Rádio e Televisão (ABERT), iniciou sua carreira nas emissoras de televisão do antigo Grupo Paulo Pimentel (GPP) e foi diretor-executivo da Rede Massa, afiliada ao Sistema Brasileiro de Televisão (SBT), ambos no Paraná. Na Associação Internacional de Radiodifusão (AIR), entidade que representa 17 mil emissoras de rádio e televisão nas Américas, Ásia e Europa, já ocupou a vice-presidência referente à América do Sul e, atualmente, é conselheiro titular da entidade ${ }^{10}$.

A jornalista Claúdia Slavieiro é casada com Daniel César Maranhão Khury, neto do deputado estadual biônico Aníbal Khury e do Desembargador Guilherme de Albuquerque Maranhão, de tradicional família de juristas e desembargadores no Paraná. Daniel Maranhão Khury é cavaleiro, representante da Federação Paranaense de Hipismo (FPrH). A prima de Claudia, Paula Mussi Pimentel, filha do empresário do ramo de comunicação Luís Mussi (concessionário de canal de TV Mercosul), Presidente do Jockey Club do Paraná, ex-secretário da Indústria e Comércio e ex-assessor especial do governador Roberto Requião) é casada com o irmão de Daniel Khury, o deputado estadual Alexandre Khury, do PSB no Paraná (OLIVEIRA, 2007; PEREIRA, 2016).

\section{MARCELO RICHA}

Para comandar a secretaria de Esporte, Lazer e Juventude, o escolhido foi Marcelo Richa, neto do ex-governador José Richa e filho do atual governador Beto Richa com Fernanda Vieira Richa. Marcelo é o atual presidente do Instituto Teotônio Villa (ITV), já foi presidente da Juventude

10 Disponível em http://www.abert.org.br/web/index.php/notmenu/item/23211-daniel-pimentel-slaviero-ereeleitopresidente-da-abert; acesso em 25/04/2017. 
do PSDB e secretário municipal da mesma pasta na gestão de Luciano Ducci. É casado com Fernanda Risseti dos Santos, lotada em cargo comissionado no TCE-PR (MIRANDA, 2016).

José Richa foi prefeito de Londrina-PR, deputado, governador do Paraná eleito em 1982 (nas primeiras eleições diretas desde 1964) e senador da República pelo PMDB (OLIVEIRA, 2007). Antes de falecer, deixou seu filho Beto Richa como um dos nomes fortes na política paranaense; o qual exerceu o cargo de prefeito de Curitiba (2005-2010) e de governador do Paraná (2011 até o presente momento).

Beto Richa é formado em Engenharia Civil pela Pontifícia Universidade Católica do Paraná (PUC-PR). Sua primeira disputa eleitoral foi em 1992 quando não se elegeu vereador pelo PSDB em Curitiba. Em 1994, foi eleito deputado estadual pelo Partido Trabalhista Brasileiro (PTB) com 22 mil votos e reeleito quatro anos mais tarde com o dobro de votos: 44.838. Também foi viceprefeito de Curitiba na gestão de Cassio Taniguchi (PFL e atual Democratas- DEM) e, de volta ao PSDB, em 2002 candidatou-se ao governo do Estado do Paraná, ficando em terceiro lugar numa disputa contra Osmar Dias (PDT) e Roberto Requião. Naquele ano, o peemedebista Requião venceu as eleições estaduais (OLIVEIRA, 2007).

Em 2004, Beto Richa elegeu-se prefeito de Curitiba pelo PSDB com 494.440 mil votos $^{11}$. Em 2008 foi reeleito com 778.514 mil votos ( $77 \%$ do total), mas renunciou ao segundo mandato de prefeito para concorrer e ser eleito em primeiro turno governador do Paraná nas eleições estaduais de 2010, também pelo PSDB ${ }^{12}$.

Beto Richa casou com a então jovem herdeira do antigo conglomerado Bamerindus ${ }^{13}$, Fernanda, filha de Tomas Edson Andrade Vieira, um dos mais importantes banqueiros do Brasil

11 Disponível em http://www.gazetadopovo.com.br/vida-publica/eleicoes/2012/memoria/2004-a-eleicao-decididapor-r-025-3dzxx1aw64sayccc06121x7wu; acesso em 24/04/2017.

12 Disponível em http://noticias.terra.com.br/eleicoes/2008/interna/0,0I3234528-El11860,00Curitiba+Beto+Richa+e+o+primeiro+prefeito+eleito+em+capitais.html; acesso em 25/04/2017.

13 "O Banco BAMERINDUS foi criado em 06/04/1943 com a denominação social de Banco Meridional da Produção S.A. [...] em 19/02/1971 adotou a denominação de Banco Bamerindus do Brasil S.A.". Ao final da década de 90, o Bamerindus foi vendido numa polêmica transação. Para maiores informações ver http://jornalggn.com.br/blog/antoniobarros/como-fhc-deu-bamerindus-ao-hsbc-documentos-da-epoca; acesso em 24/04/2017. 
na década de 1970, filho do fundador e comandante do grupo Bamerindus, Avelino Vieira, e irmão do também banqueiro José Eduardo Andrade Vieira, que foi ministro da Indústria e Comércio do governo federal de José Sarney (PMDB) na segunda metade da década de 80 e sócio do jornal Folha de Londrina. Fernanda Vieira Richa também descende da família Junqueira, uma antiga família de fazendeiros e latifundiários em Minas Gerais e São Paulo desde o período colonial (OLIVEIRA, 2012).

Um irmão do atual governador, José Richa Filho (secretário estadual de Infraestrutura e Logística na vigente gestão) foi secretário de Administração da Prefeitura de Curitiba e, antes, também foi diretor-financeiro do Departamento de Estradas de Rodagem do Governo do Paraná (DER-PR) na gestão de Jaime Lerner (PFL) e ocupou cargos na Agência de Fomento Paraná, no governo Requião em 2003. Outro filho do falecido ex-governador José Richa é Adriano Richa, que ganhou cartório no município de Campina Grande do Sul, na Região Metropolitana de Curitiba (RMC), ainda na época em que o pai era vivo (Idem).

Fazem parte ainda do primeiro escalão do governo Beto Richa, o primo Marcos Traad, no Departamento de Trânsito do Paraná (DETRAN-PR) e o primo "distante" Luiz Abi Antoun, que foi preso em um escândalo de licitações públicas, sendo citado na Operação Publicano da Polícia Federal (PF), que investiga fraudes na receita estadual. Antoun foi preso em março de 2015, acusado de corrupção em oficinas automotivas - alvo da Operação Voldemort do Grupo Especial de Combate a Crime Organizado (GAECO). A esposa de Antoun - Eloiza Fernandes Pinheiro Abi Antoun e a primeira dama Fernanda Richa foram sócias de uma faculdade privada ${ }^{14}$

Dois filhos de Antoun: Kouthar e Nemer Abi Antoun são sócios da empresa KLM Brasil com sede em Cambé. Essa empresa doou dinheiro à campanha de outro primo de Beto Richa, Gustavo Richa, pelo Partido Humanista da Solidariedade (PHS), sendo o sexto vereador mais votado de Londrina. Em 2014 Gustavo disputou uma vaga de deputado estadual sem êxito ${ }^{15}$.

\footnotetext{
${ }^{14}$ Disponível em http://www.gazetadopovo.com.br/vida-publica/esposas-de-richa-e-abi-foram-socias-em-faculdadeem-londrina-6kyr4cgi3mezu5yrt2b71x2fu; acesso em 25/04/2017.

${ }^{15}$ Disponível em http://www.gazetadopovo.com.br/vida-publica/empresa-ligada-a-primo-preso-doou-r-100-mil-paraa-campanha-de-richa-4jldjek9vkt5gnz1blme8j2bg; acesso em 25/04/2017.
} 
O vice-prefeito de Cascavel na gestão de Edgar Bueno é Mauricio Querino Theodoro que é concunhado de Luiz Abib Antoun. Ele é casado com Maria Fernandes Pinheiro, irmã de Eloisa Abi Antoun. Anteriormente Maurício já vinha ocupando cargos de destaque, como as diretorias do Serviço de Comunicações Telefônicas de Londrina (SERCOMTEL) e da Estrada de Ferro Paraná Oeste (FERROESTE) (Ibidem).

\section{JOSÉ LUPION NETO}

José Lupion Neto nasceu em 17 de julho de 1955 e é filho de José Lupion Junior e Maria Helena Ribas Lupion. José é irmão do presidente da COHAPAR, Abelardo Lupion, ex-deputado federal (DEM) e tio do deputado estadual Pedro Lupion (DEM). É casado com a defensora pública Josiane Fruet Bettini Lupion, com quem tem três filhos: Manoel Antonio, Ana Augusta e João Pedro. Lupion é formado em Direito pela PUC-PR ${ }^{16}$.

Foi responsável pelo Programa do Álcool no Centro de Desenvolvimento Industrial (CENDI) no período de 1980 a 1983, e chefe de gabinete em Curitiba do então senador Enéas Farias (PMDB) em 1983. Trabalhou na área de extração de madeira e agropecuária de 1984 a 1998 e foi diretor presidente da CEASA-PR em 1999. Foi chefe de gabinete do prefeito Cássio Taniguchi entre 2001 e 2004, presidente do Instituto Curitiba de Saúde (ICS), do PROCON-PR e presidente do Conselho Administrativo da Companhia Paranaense de Gás (COMPAGÁS) ${ }^{17}$.

\section{LUIZ FERNANDO DE SOUZA JAMUR}

Para a Secretaria de Governo foi escolhido Luiz Fernando de Souza Jamur. Em 1984 começou como estagiário na Prefeitura de Curitiba, depois foi chefe de serviço de Expedição de Alvará e Vistoria (1987/1988), chefe de serviço de Topografia (1989), chefe de serviço de

\footnotetext{
${ }^{16}$ Disponível em http://www.castro.pr.leg.br/institucional/homenagens/cidadao-honorario/ano-de-2002; acesso em $25 / 04 / 2017$

${ }^{17}$ Disponível em http://www.curitiba.pr.gov.br/conteudo/presidente-cohab/38; acesso em 25/04/2017.
} 
Fiscalização e Vistoria de Obras (1989/1991), chefe de divisão do Controle de Obras (1991/1992), gerente do Departamento de Controle de Edificações (1992/1995), gerente do Departamento de Fiscalização (1995), diretor de Fiscalização (1995/1996), superintendente da Secretaria Municipal do Urbanismo (1996) e diretor do Departamento de Controle do Uso do Solo (1997). Também foi membro titular do Conselho Municipal do Urbanismo (1997), presidente da Comissão da Regularização de Loteamentos (1997), presidente da Comissão Permanente do Comércio Ambulante (1997) e superintendente do Uso do Solo da SMU (1999). De 2002 a 2004, Jamur foi secretário municipal do Urbanismo na primeira gestão Taniguchi; posição que voltou a ocupar de 2005 a 2012 ao longo dos governos municipais de Richa e Ducci. Participou do governo do Estado na gestão Richa como diretor geral da Paraná Edificações até $2016^{18}$.

Luiz é filho de Miguel Jamur (guaratubense, nascido em 18 de novembro de 1923 e falecido em 14 de setembro de 2015), que foi prefeito do município litorâneo de Guaratuba-PR por quatro vezes (1952-1955, 1960-1963, 1969-1972 e 2005-2008) passando pelo antigo PSD, ARENA e Partido Trabalhista do Brasil (PT do B). Além de também assumir a prefeitura em diversas ocasiões quando era vice-prefeito em 1997-2000 e 2001-2004. Seu irmão Nicolau Jamur Sobrinho foi vereador de Guaratuba pelo antigo PSD entre 1956 e $1968^{19}$.

Miguel Jamur foi casado com Esther de Souza Jamur, tiveram quatro filhos: Luiz Carlos, Miguel Filho, Luiz Fernando e Paulo Roberto. Em 2005, quando prefeito de Guaratuba, Jamur empregava ao menos 19 parentes diretos em cargos municipais, do último ao primeiro escalão. Além disso, muitos dos parentes de Jamur recebiam gratificação por cargo comissionado (o que pode até duplicar o salário). É o caso de Miguel Jamur Filho, filho do prefeito e ouvidor do município. Outro filho do prefeito, Paulo Roberto Jamur, ocupava o cargo de secretário da

\footnotetext{
18 Disponível em http://www.gazetadopovo.com.br/vida-publica/eleicoes/2016/saiba-quem-faz-parte-da-equipe-detransicao-de-greca-1-reuniao-e-nesta-quinta-4biddl194ecfsqkbv6adkrp7f; acesso em 25/04/2017.

19 Disponível em http://www.gazetadopovo.com.br/vida-publica/miguel-jamur-reassume-prefeitura-de-guaratubabar4kyd3sudlxz4sztdd1ns5q; acesso em 25/04/2017.
} 
Fazenda. Ester Jamur, primeira dama de Guaratuba, também tinha um cargo comissionado. A lista de parentes continua com netos, primos, sobrinhos e alguns cônjuges desses ${ }^{20}$.

\section{DORA FICINSKI PIZZATO}

Para o ICS do segundo governo municipal de Greca de Macedo, a escolhida foi Dora Ficinski Pizzato; que é esposa de Luciano Pizzato, candidado a vice-prefeito na chapa de Maria Vitória Barros e membro de família tradicional no ramo madeireiro paranaense desde o início do século XX.

Luciano Pizzatto ${ }^{21}$ nasceu em Curitiba no dia 23 de março de 1957, filho de Douglas Pedro Pizzatto e de Consuelo Utrabo Pizzatto. Luciano foi aluno da Escola Técnica Federal do Paraná (ETFPR). Em 1974 começou a estudar eletrônica e dois anos depois ingressou no curso de engenharia florestal da UFPR. Paralelamente trabalhou como repórter, cobrindo o setor madeireiro no Brasil. De 1983 a 1985 foi membro da diretoria do Sindicato do Comércio Atacadista de Madeiras do Paraná e presidente da Associação Paranaense dos Engenheiros Florestais. Sócio gerente da empresa Reflora em 1984, também coordenou durante um ano o grupo florestal do Conselho Industrial e Comercial do Paraná (COIND-PR), além de ter sido conselheiro da Federação Patronal e do Conselho de Desenvolvimento Territorial do Litoral do Paraná. Em 1985 assumiu a vice-presidência da Sociedade Brasileira de Engenheiros Florestais, e desse ano até 1988 integrou o conselho superior do COIND-PR.

Filiado ao PMDB, em 1986 candidatou-se a deputado estadual constituinte e obteve uma suplência. De 1988 a 1989, dirigiu o departamento de parques nacionais e reservas equivalentes do Instituto Brasileiro do Desenvolvimento Florestal (IBDF) - posteriormente Instituto Brasileiro do Meio Ambiente e dos Recursos Renováveis (IBAMA). Em 1990 elegeu-se deputado federal pelo extinto Partido da Reconstrução Nacional (PRN). Empossado em fevereiro do ano seguinte, transferiu-se do PRN para o PFL. No pleito de outubro de 1998, foi mais uma vez reeleito deputado

\footnotetext{
${ }^{20}$ Disponível em http://www.tribunapr.com.br/noticias/politica/prefeito-emprega-19-pessoas-da-familia/; acesso em 20/04/2017.

21 As informações biográficas de Luciano Pizzatto que não foram referenciadas estão disponíveis em http://www.fgv.br/cpdoc/acervo/dicionarios/verbete-biografico/luciano-pizzatto; acesso em 21/04/2017.
} 
federal pela mesma legenda. Em 2002 candidatou-se ao Senado pelo PFL ficando em quarto lugar. Em 2006 candidatou-se novamente à Câmara dos Deputados pelo mesmo partido e obteve uma suplência.

Em março de 2007, com a refundação do antigo PFL para DEM, Luciano filiou-se ao novo partido. Assumiu o mandato entre dezembro de 2007 e julho de 2008 em virtude do afastamento do titular, Alceni Guerra, e posteriormente, entre fevereiro e junho de 2009. Assumiu a diretoria da COMPAGÁS durante parte do primeiro governo Richa. Foi candidato a vice-prefeito na chapa com Maria Victória Barros no pleito de 2016. Entre os candidatos a vice, era aquele que se declarava mais rico com $\mathrm{R} \$ 7,2$ milhões em bens (PEREIRA, 2016).

O casal Luciano e Dora teve três filhos. Um dos filhos, Pedro Pizzato, foi candidato a deputado federal em 2014 pelo DEM obtendo 9.076 votos, não sendo eleito naquela ocasião 22 .

\section{RODOLPHO ZANNIN FEIJÓ}

Rodolpho Zannin Feijó, curitibano, com cidadania brasileira e italiana, viveu 6 anos na Europa. Graduado em Comunicação pela PUC-PR, foi continuar sua formação em universidades da Inglaterra. Em Manchester, especializou-se em mídia interativa ${ }^{23}$.

Filho do publicitário Almir Feijó e da ex-vereadora Marlene Zannin. Com 19 anos, Marlene Zannin decidiu morar em Curitiba em 1974, depois de ser aprovada para ingressar no curso de Geografia da UFPR. Fez parte do movimento estudantil e foi vice-presidente do Diretório Central de Estudantes (DCE) da UFPR. Formou-se em Direito pela Faculdade Curitiba. Foi vereadora de Curitiba entre 1983 e 1988 pelo PMDB $^{24}$, secretária municipal do Meio Ambiente de Curitiba em 1985, assessora especial da Casa Civil do Governo do Paraná entre 1989 e 1994 e diretora do

22 Disponível em https://noticias.uol.com.br/politica/politicos-brasil/2014/deputado-federal/pr/08011985-pedropizzatto.htm; acesso em 25/04/2014.

${ }^{23}$ Disponível em http://www.aroldomura.com.br/?p=7618; acesso em 25/04/2017.

${ }^{24}$ Disponível em http://www.dhpaz.org/dhpaz/depoimentos/detalhe/46/nao-tinha-tempo-ruim-qualquer-coisa-queprecisasse-os-estudantes-estavam-sempre-prontos-para-enfrentar-a-policia-cotidianamente; acesso em 29/04/2017. 
Instituto Ambiental do Paraná (IAP) em 1994²5. Em 2007, Marlene Zannin fez história ao tornar-se a primeira mulher que ocupou cargo de direção na Companhia Paranaense de Energia (COPEL). Dentro da empresa, criou a Diretoria de Meio Ambiente e Cidadania Empresarial ${ }^{26}$. Atualmente mora em sua cidade natal, Urussanga em Santa Catarina.

Almir Feijó foi redator (e locutor) de noticiários da rádio Colombo. Entre 1971 e 1975 foi para o Canal 12 (da antiga TV Paranaense - atual Rede Paranaense de Comunicação / RPC afiliada da Rede Globo no Paraná) e depois para o jornal Diário do Paraná. Em 1977 abriu uma agência local da Standard, Ogilvy e Mather. Foi diretor de criação da Gemini, redator da Opus e da Exclam Propaganda. Em 1986 passa a dedicar-se ao marketing político, inclusive com muitas campanhas junto às candidaturas Roberto Requião ${ }^{27}$.

\section{VANESSA VOLPI BELEGGARD PALÁCIOS}

Vanessa Volpi Bellegard Palácios, que era funcionária comissionada na Casa Civil na gestão de Beto Richa, também foi assessora jurídica da campanha de Greca de Macedo e agora será a Procuradora do Município ${ }^{28}$.

Em 2015 foi nomeada por Beto Richa para integrar a Junta Administrativa de Recursos de Infrações (JARI). No início do governo richista foi para o ParanáCidade. Vanessa é conhecida por fazer parte do escritório Pereira Gionédis ${ }^{29}$ e foi defensora assídua do golpe jurídico parlamentar de $2016^{30}$

25

https://www.facebook.com/marzannin/about?lst=100002217403410\%3A100001216445172\%3A1493686251\&section =relationship\&pnref=about; acesso em 28/04/2017.

26 Disponível em http://www.fabiocampana.com.br/2009/01/candidatos-a-diretor-de-meio-ambiente-da-copel/; acesso em 28/04/2017.

${ }^{27}$ Disponível em http://www.oradiodoparana.com.br/crbst 39.html; acesso em 28/04/2017.

${ }^{28}$ Disponível em http://www.curitiba.pr.gov.br/conteudo/secretario-pgm/40; acesso em 28/04/2017.

${ }^{29}$ Disponível em http://www.gazetadopovo.com.br/vida-publica/eleicoes/2016/saiba-quem-faz-parte-da-equipe-detransicao-de-greca-1-reuniao-e-nesta-quinta-4biddl194ecfsqkbv6adkrp7f; acesso em 25/04/2017. 
A família Volpi possui membros no TJ-PR, no TCE-PR e também em cartórios e escritórios de Advocacia e Arquitetura. Adeodato Arnaldo Volpi foi membro do secretariado dos governos Ney Braga (extinto Partido Democrata Cristão - PDC e ARENA) e Paulo Pimentel na década de 1960. Nasceu em 1912, filho de Ângelo Volpi e Colomba Bertoldi. Ingressou em 1930 na vida pública como serventuário da Justiça e em 1952 foi nomeado 7o Tabelião de Notas da Capital. Em 1947 foi eleito vereador de Curitiba pela União Democrática Nacional (UDN), sendo reeleito em 1951. Entre 1961 e 1964 foi presidente e diretor da Companhia de Desenvolvimento do Paraná (CODEPAR), e teve passagens pelo antigo Banco do Estado do Paraná (BANESTADO) ${ }^{31}$. Foi designado vice-prefeito de Curitiba entre 1964 e 1966 (CORDEIRO, 2005, p. 119).

A esposa de Adeodato Volpi era Zulmira Marcassa Volpi. Tiveram duas filhas: Regina Helena Volpi (que foi casada com Luiz Malucelli) e Aliete Maria Volpi (que foi casada com Jaime Prosdóscimo). Seu irmão Renato Volpi assumiu o 70 Tabelião de Notas em 1960 e depois o repassou para o sobrinho Ângelo Volpi Neto que assumiu em data incerta ${ }^{32}$. Os Volpi também estão no TJ-PR com Letícia Volpi da Silva e Cyntia Volpi Suplicy, e no TCE-PR com Ester Volpi ${ }^{33}$.

\section{JOSÉ ANTONIO ANDREGUETTO}

Para a presidência da URBS, o prefeito eleito Greca de Macedo escolheu Jose Antonio Andreguetto. Natural de Curitiba e formado em Economia pela UFPR, Andreguetto é antigo

\footnotetext{
30 Disponível em https://www.facebook.com/permalink.php?story fbid=240403276309145\&id=240342542981885; acesso 30/04/2017.

31 No ano 2000, em meio a muitas polêmicas, o BANESTADO foi adquirido pelo Banco Itaú. Maiores detalhes ver http://www.fetecpr.org.br/privatizacao-do-banco-banestado-completa-15-anos/; acesso em 24/04/2017.

32 Disponível em http://www.volpi.com.br/conteudo/133; acesso em 29/04/2017.

${ }^{33}$ Disponível em https://portal.tjpr.jus.br/transparencia/AnexoV 1406 35.html; acesso em 29/04/2017.
} 
quadro do grupo político que reassumiu a Prefeitura de Curitiba em 2016 e já foi diretor de transportes da URBS entre abril de 2005 e março de $2006^{34}$.

Em seu currículo constam passagens no IAP, na Secretaria de Estado do Meio Ambiente e Recursos Hídricos (na qual também foi secretário estadual na segunda gestão de Jaime Lerner), no Conselho Estadual de Sanidade Agropecuária (CONESA) e no Conselho Nacional do Meio Ambiente (CONAMA) e no alto escalão da Companhia de Saneamento do Paraná (SANEPAR). Também presidiu o Conselho de Administração do IAP, o Conselho de Administração da Superintendência de Desenvolvimento de Recursos Hídricos e Saneamento Ambiental (SUDERHSA), o Conselho Estadual do Meio Ambiente (CEMA) e o Conselho de Desenvolvimento do Litoral Paranaense $(\text { COLIT })^{35}$.

Na sequência de sua trajetória, Andreguetto esteve à frente da desativação do aterro da Caximba, na periferia de Curitiba ${ }^{36}$, e no ano de 2011 foi chefe de gabinete do então prefeito de Curitiba Luciano Ducci. Quando Ducci se elege deputado federal nas eleições de 2014, Andreguetto segue para Brasília e assume a chefia de seu gabinete na Câmara Federal ${ }^{37}$. Filiado ao PSB, a atual presidente da URBS chegou foi cogitado para o cargo de vice-prefeito de capital paranaense na chapa de Greca de Macedo nas eleições de 2016. Mas a vaga acabou ocupada por Eduardo Pimentel Slaviero ${ }^{38}$.

34 Disponível em http://www.thecities.com.br/Brasil/Paran\%C3\%A1/Curitiba/PoderP\%C3\%BAblico/Prefeitura/Administra\%C3\%A7\%C3\%A3o/Secretarias/Meio-Ambiente/840/; acesso em 27/04/2017.

35

http://www.sanepar.com.br/sanepar/calandrakbx/filesmng.nsf/ABF593B2D91E80298325729600465B3F/\$File/IAN20 02.pdf?OpenElement; acesso em 27/04/2017.

36 Disponível em http://www.gazetadopovo.com.br/vida-e-cidadania/a-caximba-em-estado-de-gracabaq4kfdcu8xqwphdv272zdnim; acesso em 27/04/2017.

37 Disponível em http://www.fabiocampana.com.br/2011/01/andreguetto-na-chefia-de-gabinete-de-luciano-ducci/; acesso em 27/04/2017.

${ }^{38}$ Disponível em http://www.esmaelmorais.com.br/2016/07/vice-de-greca-sera-do-psb/; acesso em 27/04/2017. 
Em termos familiares, Jose Antonio Andreguetto é filho de do advogado Christiano Osvaldo Andreguetto, falecido em 2 de abril de $2017^{39}$. Christiano assumiu cargo comissionado na Secretaria de Estado da Agricultura e do Abastecimento, em abril de 2007, no segundo governo Requião (PARANÁ, 2007) e foi casado com Elizabete Maria Neiva Negrão ${ }^{40}$, madrasta do atual presidente da URBS.

Outros membros da família Andreguetto estão presentes no funcionalismo público direta e indiretamente. Carlos Alberto Andreguetto (talvez irmão, primo ou sobrinho de José Antonio Andreguetto) é executivo da empresa Solis Tecnologia Ltda. e foi indiciado por peculato, formação de quadrilha e falsidade ideológica em investigação da Operação Sinapse da Polícia Federal; que apurava desvios de recursos do Instituto Federal do Paraná (IFPR) em $2013^{41}$. Carlos é casado com Monica Utri Andreguetto ${ }^{42}$, que já trabalhou na Prefeitura de Curitiba ${ }^{43}$. O filho do casal, Renan Utri Andreguetto é funcionário do IAP44.

Rafael Andreguetto ${ }^{45}$ é sobrinho de Carlos e Monica. Rafael é consultor na área de Turismo vinculado à empresa RCL Planejamento e já prestou serviços na Secretaria Estadual de Esporte e Turismo (SEET). "Atualmente é Diretor Executivo da Agência de Desenvolvimento do Turismo Sustentável do Litoral do Paraná (ADETUR LITORAL)"46. Matrimoniou-se com a advogada Luciana Maria Negrão Gandra, filha de Elizabete Maria Neiva Negrão Andreguetto. Luciana é atualmente

39 Disponível em http://www.tribunapr.com.br/noticias/falecimentos/falecimentos-02042017/; acesso em 27/04/2017.

${ }^{40}$ Disponível em http://www.radaroficial.com.br/d/6356314003341312; acesso em 22/01/2017.

${ }^{41}$ Disponível em https://pt.slideshare.net/arykara7002/relatorio-sinapse; acesso em 27/04/2017.

${ }^{42}$ Disponível em https://www.facebook.com/carlos.andreguetto.7; acesso em 27/04/2017.

${ }^{43}$ Disponível em https://www.facebook.com/monica.utri; acesso em 27/04/2017.

${ }^{44}$ Disponível em https://www.facebook.com/renan.andreguetto?fref=ts; acesso em 27/04/2017.

${ }^{45}$ Disponível em https://www.facebook.com/rafael.andreguetto?pnref=lhc; acesso em 27/04/2017.

${ }^{46}$ Disponível em http://www.rclplanejamento.com.br/rafael-andreguetto/; acesso em 27/04/2017. 
coordenadora de projetos da Fundação Araucária e já trabalhou nos escritórios Bettega, Mafra \& Sperandio Advogados e Abdala, Brandalize \& Gandra Advocacia ${ }^{47}$.

Nos levantamentos realizados também identificamos Paulo Andreguetto como médico do TJ-PR ${ }^{48}$. Mas diante das fontes disponíveis, não foi possível identificar o grau de parentesco com Jose Antonio Andreguetto.

\section{JOÃO ALFREDO COSTA FILHO}

O Chefe de Gabinete de Greca de Macedo será João Alfredo Costa Filho, dono do serviço de ambulâncias Plus Santé, Costa Filho foi um dos coordenadores da campanha grequista à prefeitura em 2016, ao lado do advogado Giovani Gionédis. Foi diretor de futebol do Clube Atlético Paranaense (2012-2013) e candidato derrotado pela chapa de Mario Celso Petraglia à presidência do Conselho Administrativo do clube em $2014^{49}$.

Conforme a imprensa local, o "apoio de Beto Richa a Rafael Greca foi fechado num café da manhã na casa do empresário João Alfredo Costa Filho que reuniu um grupo de conhecidos apoiadores financeiros de campanhas anteriores" ${ }^{\prime 50}$. Seu pai Alfredo Costa foi vereador da primeira, segunda, terceira e quarta composição da Câmara Municipal de Ibaiti. Seu avô Ananias Costa foi um dos fundadores do município de Ibaiti-PR ao final de 1923, onde foi escrivão policial, tabelião e instalou uma farmácia, que mais tarde seria ocupação de seus filhos mais velhos. Sua

\footnotetext{
${ }^{47}$ Disponível em https://www.facebook.com/luciana.gandra.9; acesso em 27/04/2017.

48

https://www.tjpr.jus.br/home?p_p id=101\&p_p lifecycle=0\&p_p state=maximized\&p_p mode=view\& 101 struts action=\%2Fasset publisher\%2Fview content\& 101 returnToFullPageURL=\%2F\& 101 assetEntryld=5423009\& 101 t ype=document\&redirect=https\%3A\%2F\%2Fwww.tipr.jus.br\%2Fhome\%3Fp p id\%3D3\%26p p lifecycle\%3D0\%26p p state\%3Dmaximized\%26p p mode\%3Dview\%26 3 groupld\%3D0\%26 3 keywords\%3DAndreguetto\%26 3 struts a ction\%3D\%252Fsearch\%252Fsearch\%26 3 redirect\%3D\%252F; acesso em 27/04/2017.
}

49 Disponível em http://www.gazetadopovo.com.br/vida-publica/eleicoes/2016/saiba-quem-faz-parte-da-equipe-detransicao-de-greca-1-reuniao-e-nesta-quinta-4biddl194ecfsqkbv6adkrp7f; acesso em 25/04/2017.

${ }^{50}$ Disponível em http://cicerocattani.com.br/dono-de-ambulancias-leva-beto-greca/; acesso em 21/04/2017. 
avó Janina Gonevino Costa, natural de Verona na Itália, foi a primeira professora municipal de Barra Bonita-SP em $1927^{51}$.

\section{MARCELO SIMAS DO AMARAL CATTANI}

Marcelo Simas do Amaral Catani é graduado em Comunicação Social pela PUCPR, com pósgraduação e especialização em Marketing de Serviços pela Fundação Getúlio Vargas no Rio de Janeiro (FGV-RJ). De 2005 a 2008, foi diretor de marketing da Fundação Cultural de Curitiba. No mesmo período foi presidente do Fundo Municipal de Cultura. Em 2003 e 2004, Cattani foi diretor de marketing da Prefeitura de Curitiba. Também trabalhou no grupo Inepar, na Secretaria Estadual da Comunicação Social e no jornal Correio de Notícias. Em 2009 foi empossado como novo secretário municipal da Comunicação Social na segunda gestão estadual de Beto Richa ${ }^{52}$.

No governo do Estado, acompanhou Richa como secretário de Comunicação Social por quatro anos e três meses ${ }^{53}$. Em julho de 2016 assumiu a campanha à prefeitura do candidato Greca de Macedo. É filho do jornalista de longa data Cícero Cattani ${ }^{54}$; o qual esteve presente em diversas campanhas políticas.

${ }^{51}$ Disponível em http://joaobourbon.blogspot.com.br/2016/02/ibaiti-rainha-das-colinas-sua-historia.html; acesso em 29/04/2017. http://www.crn1.com.br/noticias/36094/veja o perfil dos secretarios de beto richa com dois mouraoenses ent re eles douglas fabricio e ricardo soavinski.html; acesso em 29/04/2017.

${ }^{53}$ Disponível em http://g1.globo.com/pr/parana/noticia/2015/03/secretario-de-comunicacao-social-do-parana-pededemissao.html; acesso em 29/04/2017.

${ }^{54}$ Disponível em http://cicerocattani.com.br/sobre/; acesso em 29/04/2017. 


\section{TATIANA TURRA}

O prefeito eleito Rafael Greca de Macedo confirmou como presidente do Instituto Municipal de Turismo a atual diretora executiva do Curitiba Convention \& Visitors Bureau, Tatiana Turra 55

Tatiana casou-se com Luiz Henrique Bona Turra, graduado em Direito pela UFPR, sócio e Advogado do escritório nacional Vanzin e Penteado Advogados. No período de 1987 a 1994, Luiz Henrique exerceu as funções de diretor geral do Departamento de Obras do Governo do Paraná, deputado estadual, diretor presidente da Coordenação da Região Metropolitana de Curitiba (COMEC) e assessor especial de Governo Jaime Lerner. Em decorrência da aprovação em sucessivos concursos públicos nacionais de provas e títulos, exerceu entre 2000 e 2005 as funções de Advogado da União, Procurador da Fazenda Nacional e Procurador do Estado do Paraná56.

Luiz Henrique vem de uma família de políticos vinculada ao antigo PTB e, depois, ao antigo Movimento Democrático Brasileiro (MDB). Seu pai Laudenir Turra foi um dos últimos pioneiros do Oeste do Paraná. Natural de São João do Triunfo-PR, o contabilista Laudemir viveu em Palmeira-PR e Curitiba. Chegou à capital paranaense nos anos 50, trabalhando no ramo de seguros ${ }^{57}$.

Integrante da organização brizolista Grupos dos Onze ${ }^{58}$, transferiu-se para o Oeste paranaense logo após o golpe militar de 1964. Em 1974 coordenou a eleição do irmão Lineu Turra a deputado estadual. Em 1976 e 1988 elegeu-se prefeito de Corbélia-PR e, no primeiro governo de Roberto Requião foi consultor técnico da Secretaria de Estado da Fazenda. Sua esposa, Irene Bona Turra, teve grande participação e liderança nas eleições e gestões de Laudemir Turra, e nas

55 Disponível em http://www.panrotas.com.br/noticia-turismo/gente/2017/01/nova-secretaria-quer-turismo-decuritiba-mais-cultural 143191.html; acesso em 29/04/2017.

\footnotetext{
${ }^{56}$ Disponível em https://www.escavador.com/sobre/1015758/luiz-henrique-bona-turra; acesso em 29/04/2017.

57 Disponível em http://www.fabiocampana.com.br/2013/07/morre-laudemir-turra-um-dos-pioneiros-do-oeste/; acesso em 29/04/2017.

58 "Movimento também conhecido como Grupos dos Onze Companheiros, criado em fins de outubro de 1963, pelo então deputado federal Leonel Brizola, com o objetivo de lutar pela implantação das chamadas reformas de base (agrária, urbana, educacional, bancária etc.) preconizadas pelo presidente João Goulart, e pela "libertação do Brasil da espoliação internacional". Foi desarticulado após o movimento político-militar de 31 de março de 1964". Disponível em http://www.fgv.br/cpdoc/acervo/dicionarios/verbete-tematico/grupos-dos-onze; acesso em 24/04/2017.
} 
eleições para deputado estadual do filho Luiz Henrique Bona Turra e do cunhado Lineu Mansani Turra. Em 1996, Irene foi eleita vereadora de Corbélia-PR com uma das maiores votações da história do município. Faleceu em 25 de março de $2016^{59}$

\section{VITOR PUPPI}

O futuro secretário de Finanças, Vitor Puppi, que foi diretor-geral da Secretaria Estadual de Fazenda, é formado em Direito pela UFPR e cursou mestrado em Direito Empresarial na Universidade de Berkeley em 2013. Desde 2004, Vitor também integra conselho da seccional paranaense da Ordem dos Advogados do Brasil (OAB-PR). É Procurador do Estado do Paraná e exerceu o cargo de Diretor Geral da Secretaria de Estado da Fazenda do Paraná entre 2013 e $2014^{60}$.

A família Puppi possui uma trajetória marcante na política de Campo Largo-PR; município da RMC (MACHADO; CAPRARO, 2016). O advogado e ex-gerente da Caixa Econômica Federal (CEF) Newton Puppi (falecido em 5 de abril de 2010) "foi três vezes prefeito de Campo Largo, nas gestões 1963/1969, 1977/1982 e 1997/2000". No ano de 1974, Newton "exerceu o cargo de Diretor do Departamento de Aplicação do Capital" do Instituto de Previdência e Assistência aos Servidores do Estado (IPE), nessa ocasião, foi nomeado pelo então "governador Emílio Hoffmann Gomes" e também, e "foi conselheiro do" TCE-PR ${ }^{61}$.

O filho de Newton Puppi, Marcelo Fabiani Puppi, foi vereador de Campo Largo-PR entre 2005 e 2008, exerceu a Presidência da Câmara (2005-2006) e não conseguiu a reeleição em 2008. E 2016 foi eleito prefeito de Campo Largo pelo DEM. Marcelo cursou Filho do "Direito pela UFPR" e "se especializou em Ciências Políticas, na Academia Internacional de Liberdade e

\footnotetext{
${ }^{59}$ Disponível em http://www.fabiocampana.com.br/2016/03/morreu-irene-bona-turra/; acesso em 29/04/2017.

${ }^{60}$ Disponível em http://www.curitiba.pr.gov.br/conteudo/secretario-smf/48; acesso em 28/04/2017.

${ }^{61}$ Disponível em http://www.folhadecampolargo.com.br/vernoticia.php?id=2453; acesso em 29/04/2017.
} 
Desenvolvimento de Adolescentes, em Lisboa e na Academia Internacional de Dirigentes, na Alemanha" 62 .

É possível constatar a significativa presença de membros da família Puppi no TJ-PR. João Domingos Puppi, que nasceu em “Campo Largo, foi promovido à desembargador em 2007. João “é filho do desembargador (falecido) Clementino Schiavon Puppi" e já atuou como juiz nas comarcas de Araucária, Capanema, Colombo, Curitiba e Sengés ${ }^{63}$. Também identificamos a "juíza Maria Cecília Puppi, do Juizado Especial de Ponta Grossa”64 e Vanessa Flávia Puppi Moro Carias de Araújo, que exerce "cargo de provimento em comissão de Secretário de Desembargador, símbolo DAS-4, do Gabinete do Desembargador Renato Naves Barcellos" desde 2014 (PARANÁ, 2014, p. 3).

Diante das fontes disponíveis, não foi possível identificar o exato grau de parentesco do secretário Vitor Puppi com os ramos familiares citados nesse tópico.

\section{CONSIDERAÇÕES FINAIS}

Com as informações preliminarmente apuradas é possível identificar que o capital político familiar enquanto um constante recurso mobilizador. Nessa lógica, "a esfera da política" é "um dos espaços em que a família torna-se estratégica no sentido de ampliação dos capitais: político, econômico e familiar" (MONTEIRO, 2016, p. 563).

Assim, os secretários da gestão Greca de Macedo em 2017, em suas consistentes trajetórias junto aos cargos e às influências nas estruturas estatais do Paraná, oferecem situações interessantes para estudos "da repartição desigual dos poderes e dos centros de decisão", que averigua "o acréscimo do poder de uns [...] relativamente à redução do poder de outros". Conforme Saint Martin, "a análise sociológica deverá ter por objeto os desacordos e as lutas

${ }^{62}$ Disponível em http://www.folhadecampolargo.com.br/vernoticia.php?id=11684; acesso em 29/04/2017.

$63 \quad$ Disponível em http://www.migalhas.com.br/Quentes/17,MI46947,11049TJPR+Joao+Domingos+Puppi+novo+Desembargador; acesso em 29/04/2017.

${ }^{64}$ Disponível em https://www.facebook.com/blogdamarelimartins/posts/923196461146663; acesso em 30/04/2017. 
decorrentes dessa desigual distribuição de poderes a par das próprias reestruturações" (SAINTMARTIN, 1995, p. 1023).

O dueto dominação / mobilidade social "resulta não apenas da herança de patrimônio, mas também de um sem-número de outras coisas (tempo livre, rede de relações sociais, hábitos culturais, mais chance de errar e recomeçar etc.)". Tais elementos possibilitam oportunidades de ascensão social e apresentam, "de alguma maneira, têm relação com a riqueza das gerações passadas"65. Assim, as fronteiras, as trajetórias, as rupturas e as reconversões cerram uma relação sistemática alicerçada por estruturas familiares. Portanto, emerge uma interessante ocasião favorável para ressaltar a relevância da família nas análises políticas e sociais

\section{REFERÊNCIAS}

BOURDIEU, P. (1996). Razões práticas: sobre a teoria da ação. Campinas: Papirus.

CORDEIRO, V. M. (2005). Paulo Pimentel: um político do século XX e XXI. 196 f. Dissertação (Mestrado em Sociologia) Setor de Ciências Humanas, Letras e Artes da Universidade Federal do Paraná, Curitiba.

FAORO, R. (2001). Os donos do poder - Formação do patronato político brasileiro. Rio de Janeiro: Globo.

LABACHE, L.; SAINT-MARTIN, M. (2008). "Fronteiras, trajetórias e experiências de ruptura". Educação e Sociedade, mai/ago, vol. 29, no 103, p. 333-354.

MACHADO, V. H.; CAPRARO, M. Z. (2016). "Os donos do poder em Campo Largo: Quem são?". Revista NEP - Núcleo de Estudos Paranaenses da UFPR, mai, v.2, n.2, p. 118-136.

MIRANDA, E. S. (2016). “A bancada dos júnior (es): famílias e parentesco no Legislativo Paranaense durante o governo Beto Richa". Revista NEP - Núcleo de Estudos Paranaenses da UFPR, mai, v.2, n.2, p. 580-595.

MACEDO, J. N. A.; BACELLAR, E. M. (1998). Genealogia de Manoel Ribeiro de Macedo. Curitiba: [s/ed].

PEREIRA, F. M. (2016). "Famílias políticas tradicionais dominam as eleições à Prefeitura de Curitiba em 2016". Revista NEP - Núcleo de Estudos Paranaenses da UFPR, set, v.2, n.4, p. 35-50.

\footnotetext{
${ }^{65}$ Disponível em http://piaui.folha.uol.com.br/materia/piketty-e-nos/; acesso em 30/04/2017.
} 
MATOS, H. (2009). Capital social e comunicação: interfaces e articulações. São Paulo: Summus.

MONTEIRO, J. M. (2016). "Parentesco e representação política: a força do capital político familiar na 54a legislatura no Congresso Nacional". Revista NEP - Núcleo de Estudos Paranaenses da UFPR, mai, v.2, n.2, p. 561-579.

OLIVEIRA, R. C (2012). Na teia do nepotismo: sociologia política das relações de parentesco e poder político no Paraná e no Brasil. Curitiba: Insigth.

(2007). "Famílias, poder e riqueza: redes políticas no Paraná em 2007". Sociologias, jun/dez, n.18, pp.150-169.

PARANÁ (2014). Decreto no 590, de 9 de abril de 2014. Nomeação de Vanessa Flávia Puppi Moro Carias de Araújo, para cargo de provimento em comissão de Secretário de Desembargador. Disponível em https://www.jusbrasil.com.br/diarios/68836657/djpr-09-04-2014-pg-3; acesso em 29/04/2017.

(2007). Decreto no 458, de 28 de março de 2007. Nomeação de Christiano Osvaldo Andreguetto, para o cargo de assistente técnico, da Secretaria de Estado da Agricultura e do Abastecimento - SEAB, e exoneração de Fante de Souza Farias. Disponível em http://www.leisestaduais.com.br/pr/decreto-n-458-2007-parana-nomeacao-de-christianoosvaldo-andreguetto-para-o-cargo-de-assistente-tecnico-da-secretaria-de-estado-daagricultura-e-do-abastecimento-seab-e-exoneracao-de-fante-de-souza-farias; acesso em 27/04/2017.

SAINT MARTIN, M. (1995). "Reconversões e reestruturações das elites: o caso da aristocracia francesa”. Análise Social, vol xxx, no 134, p. 1023-1039.

STONE, L. (2011). “Prosopografia”. Revista de Sociologia e Política, jun., vol. 19, no 39, p. 115-137.

\section{Documentos de acesso exclusivo em meio eletrônico}

"35 - Portal da Transparência https://portal.tipr.jus.br/transparencia/AnexoV 1406 35.html; acesso em 29/04/2017.

"2004: A eleição decidida por R\$ 0,25" - Disponível em http://www.gazetadopovo.com.br/vidapublica/eleicoes/2012/memoria/2004-a-eleicao-decidida-por-r-0253dzxx1aw64sayccc0612Ix7wu; acesso em 24/04/2017.

"A Caximba em estado de graça" - Disponível em http://www.gazetadopovo.com.br/vida-ecidadania/a-caximba-em-estado-de-graca-baq4kfdcu8xqwphdv272zdnim; acesso em 27/04/2017. 
“ALIADOS DE RICHA ABOCANHAM 10 DOS 24 CARGOS DO PRIMEIRO ESCALÃO" - Disponível em http://www.poderjuridico.com.br/aliados-de-richa-abocanham-10-dos-24-cargos-deprimeiro-escalao-de-greca/; acesso em 20/04/2017.

"Almir Feijó" - Disponível em http://www.oradiodoparana.com.br/crbst 39.html; acesso em 28/04/2017.

"Andreguetto na chefia de gabinete de Luciano Ducci" - Disponível em http://www.fabiocampana.com.br/2011/01/andreguetto-na-chefia-de-gabinete-de-lucianoducci/; acesso em 27/04/2017.

"Ano de 2002" - Disponível em http://www.castro.pr.leg.br/institucional/homenagens/cidadaohonorario/ano-de-2002; acesso em 25/04/2017.

"Assim a ONU prepara seus quadros, como Rodolpho, um curitibano" - Disponível em http://www.aroldomura.com.br/?p=7618; acesso em 25/04/2017.

"Blog da Marelli Martins" - $\quad$ Disponível em https://www.facebook.com/blogdamarelimartins/posts/923196461146663; acesso em 30/04/2017.

"Carlos Andreguetto" - Disponível em https://www.facebook.com/carlos.andreguetto.7; acesso em 27/04/2017.

"Carreira de Jose Antonio Andreguetto" - Disponível em http://www.thecities.com.br/Brasil/Paran\%C3\%A1/Curitiba/Poder-P\%C3\%BAblico/PoderExecutivo-Municipal/Mandato-2013-2016/Administra\%C3\%A7\%C3\%A3o/Secretarias/MeioAmbiente/840/; acesso em 27/04/2017.

"Como FHC deu Bamerindus ao HSBC - documentos da época" - Disponível em http://jornalggn.com.br/blog/antoniobarros/como-fhc-deu-bamerindus-ao-hsbcdocumentos-da-epoca; acesso em 24/04/2017.

"Companhia de Habitação Popular de Curitiba" - Disponível em http://www.curitiba.pr.gov.br/conteudo/presidente-cohab/38; acesso em 25/04/2017.

"Curitiba: Beto Richa é o primeiro prefeito eleito em capitais" - Disponível em http://noticias.terra.com.br/eleicoes/2008/interna/0,0l3234528-El11860,00-

Curitiba+Beto+Richa+e+o+primeiro+prefeito+eleito+em+capitais.html; acesso em 25/04/2017.

"Daniel Pimentel Slaviero é reeleito presidente da Abert" - Disponível em http://www.abert.org.br/web/index.php/notmenu/item/23211-daniel-pimentel-slaviero-ereeleitopresidente-da-abert; acesso em 25/04/2017. 
"Diário PR - $\quad$ Tribunal de Justiça" - $\quad$ Disponível em http://www.radaroficial.com.br/d/6356314003341312; acesso em 22/01/2017.

"Dono de ambulâncias leva Beto a Greca" - Disponível em http://cicerocattani.com.br/dono-deambulancias-leva-beto-greca/; acesso em 21/04/2017.

“Empresa ligada a 'primo' preso doou R\$ 100 mil para a campanha de Richa" - Disponível em http://www.gazetadopovo.com.br/vida-publica/empresa-ligada-a-primo-preso-doou-r-100mil-para-a-campanha-de-richa-4jldjek9vkt5gnz1blme8j2bg; acesso em 25/04/2017.

"Esposas de Richa e Abi foram sócias em faculdade em Londrina" - Disponível em http://www.gazetadopovo.com.br/vida-publica/esposas-de-richa-e-abi-foram-socias-emfaculdade-em-londrina-6kyr4cgi3mezu5yrt2b71x2fu; acesso em 25/04/2017.

"FALECIMENTOS DO DIA (02/04/2017)" - $\quad$ Disponível em http://www.tribunapr.com.br/noticias/falecimentos/falecimentos-02042017/; acesso em 27/04/2017.

"Greca será processado por falhas da nau capitânea" - Disponível em http://www.dgabc.com.br/Noticia/257838/greca-sera-processado-por-falhas-da-naucapitanea; acesso em 24/04/2017.

"GRUPOS DOS ONZE" - Disponível em http://www.fgv.br/cpdoc/acervo/dicionarios/verbetetematico/grupos-dos-onze; acesso em 24/04/2017.

"Histórico" - Disponível em http://www.volpi.com.br/conteudo/133; acesso em 29/04/2017.

"Jaime Lerner" - $\quad$ Disponível em http://www.casacivil.pr.gov.br/modules/conteudo/conteudo.php?conteudo=91; acesso em 21/04/2017.

"Ibaiti, Rainha das Colinas, Sua História" - Disponível em http://joaobourbon.blogspot.com.br/2016/02/ibaiti-rainha-das-colinas-sua-historia.html; acesso em 29/04/2017.

"Luciana Gandra Andreguetto" - Disponível em https://www.facebook.com/luciana.gandra.9; acesso em 27/04/2017.

"Luciano Ducci assume a prefeitura de Curitiba" - Disponível em http://www.cmc.pr.gov.br/ass det.php?not=14847\#\&panel1-1; acesso em 23/04/2017.

"LUCIANO PIZZATTO" - Disponível em http://www.fgv.br/cpdoc/acervo/dicionarios/verbetebiografico/luciano-pizzatto; acesso em 21/04/2017.

"Luiz Henrique Bona Turra" - Disponível em https://www.escavador.com/sobre/1015758/luizhenrique-bona-turra; acesso em 29/04/2017. 
"MP denuncia Greca por farra na COHAPAR" - Disponível em http://www.bemparana.com.br/noticia/107221/mp-denunciara-greca-por-farra-na-cohapar; acesso em 23/04/2017.

"MP investiga jantares de Greca pagos pela COHAPAR". Disponível em http://www.bemparana.com.br/noticia/73751/mp-investiga-jantares-de-greca-pagospelacohapar; acesso em 24/04/2017.

"Marcelo Fabiano $\quad$ Puppi" - $\quad$ Disponível em http://www.folhadecampolargo.com.br/vernoticia.php?id=11684; acesso em 29/04/2017.

"Marlene Zannin" - $\quad$ Disponível em https://www.facebook.com/marzannin/about?lst=100002217403410\%3A100001216445172 \%3A1493686251\&section=relationship\&pnref=about; acesso em 28/04/2017.

"Marlene Zanin é a diretora de Meio Ambiente da Copel" - Disponível em http://www.fabiocampana.com.br/2009/01/candidatos-a-diretor-de-meio-ambiente-dacopel/; acesso em 28/04/2017.

"Miguel Jamur reassume prefeitura de Guaratuba" - Disponível em http://www.gazetadopovo.com.br/vida-publica/miguel-jamur-reassume-prefeitura-deguaratuba-bar4kyd3sudlxz4sztdd1ns5q; acesso em 25/04/2017.

"Monica Utri" - Disponível em https://www.facebook.com/monica.utri; acesso em 27/04/2017.

"Morre Irene Bona Turra" - Disponível em http://www.fabiocampana.com.br/2016/03/morreuirene-bona-turra/; acesso em 29/04/2017.

"Morre Laudemir Turra, um dos pioneiros do Oeste do Paraná" - Disponível em http://www.fabiocampana.com.br/2013/07/morre-laudemir-turra-um-dos-pioneiros-dooeste/; acesso em 29/04/2017.

"Morre Newton $\quad$ Puppi" - $\quad$ Disponível em http://www.folhadecampolargo.com.br/vernoticia.php?id=2453; acesso em 29/04/2017.

"Não tinha tempo ruim. Qualquer coisa que precisasse, os estudantes estavam sempre prontos para enfrentar a polícia cotidianamente" - Disponível em http://www.dhpaz.org/dhpaz/depoimentos/detalhe/46/nao-tinha-tempo-ruim-qualquercoisa-que-precisasse-os-estudantes-estavam-sempre-prontos-para-enfrentar-a-policiacotidianamente; acesso em 29/04/2017.

"Nova secretária quer Turismo de Curitiba mais cultural" - Disponível em http://www.panrotas.com.br/noticia-turismo/gente/2017/01/nova-secretaria-quer-turismode-curitiba-mais-cultural 143191.html; acesso em 29/04/2017. 
"Pedro Pizzatto" - Disponível em https://noticias.uol.com.br/politica/politicosbrasil/2014/deputado-federal/pr/08011985-pedro-pizzatto.htm; acesso em 25/04/2014.

"Piketty e nós" - Disponível em http://piaui.folha.uol.com.br/materia/piketty-e-nos/; acesso em $30 / 04 / 2017$.

"PREFEITO EMPREGA 19 PESSOAS DA FAMÍLIA" - Disponível em http://www.tribunapr.com.br/noticias/politica/prefeito-emprega-19-pessoas-da-familia/; acesso em 20/04/2017.

"Privatização do banco Banestado completa 15 anos" - Disponível em http://www.fetecpr.org.br/privatizacao-do-banco-banestado-completa-15-anos/; acesso em 24/04/2017.

"Procuradoria Geral do Município" - Disponível em http://www.curitiba.pr.gov.br/conteudo/secretario-pgm/40; acesso em 28/04/2017.

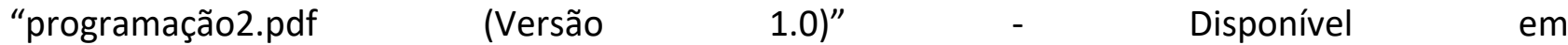
https://www.tjpr.jus.br/home?p $\mathrm{p}$ id $=101 \& \mathrm{p} p$ lifecycle $=0 \& \mathrm{p} \quad \mathrm{p}$ state=maximized\&p $\mathrm{p} \mathrm{m}$ ode=view\& 101 struts action=\%2Fasset publisher\%2Fview content\& 101 returnToFullPa geURL=\%2F\& 101 assetEntryld=5423009\& 101 type=document\&redirect=https\%3A\%2F\% 2Fwww.tjpr.jus.br\%2Fhome\%3Fp_p id\%3D3\%26p_p lifecycle\%3D0\%26p_p state\%3Dmaxi mized\%26p p mode\%3Dview\%26 3 groupld\%3D0\%26 3 keywords\%3DAndreguetto\%26 3 struts action\%3D\%252Fsearch\%252Fsearch\%26 3 redirect\%3D\%252F; acesso em 27/04/2017.

"Rafael Andriguetto" - Disponível em https://www.facebook.com/rafael.andreguetto?pnref=lhc; acesso em 27/04/2017.

"Rafael Andriguetto" - Disponível em http://www.rclplanejamento.com.br/rafael-andreguetto/; acesso em 27/04/2017.

"Relatório (Operação Sinapse)" - Disponível em https://pt.slideshare.net/arykara7002/relatoriosinapse; acesso em 27/04/2017.

"Renan Utri Andriguetto" - Disponível em https://www.facebook.com/renan.andreguetto?fref=ts; acesso em 27/04/2017.

"Roberto Requião - Senador do Paraná - Trajetória" - Disponível em http://www.robertorequiao.com.br/trajetoria-2/; acesso em 23/04/2017.

"Saiba quem faz parte da equipe de transição de Greca; 1.a reunião é nesta quinta" - Disponível em http://www.gazetadopovo.com.br/vida-publica/eleicoes/2016/saiba-quem-faz-parte-daequipe-de-transicao-de-greca-1-reuniao-e-nesta-quinta-4biddl194ecfsqkbv6adkrp7f; acesso em 25/04/2017. 
"Secretaria Municipal de Planejamento, Finanças e Orçamento" - Disponível em http://www.curitiba.pr.gov.br/conteudo/secretario-smf/48; acesso em 28/04/2017.

"Secretário de Comunicação Social do Paraná pede demissão" - Disponível em http://g1.globo.com/pr/parana/noticia/2015/03/secretario-de-comunicacao-social-doparana-pede-demissao.html; acesso em 29/04/2017.

"Serviço Público Federal / Comissão de Valores Mobiliários (CVM) / Informações Anuais (IAN) 2002 - Sanepar" - Disponível em http://www.sanepar.com.br/sanepar/calandrakbx/filesmng.nsf/ABF593B2D91E8029832572 9600465B3F/\$File/IAN2002.pdf?OpenElement; acesso em 27/04/2017.

"Sobre" - Disponível em http://cicerocattani.com.br/sobre/; acesso em 29/04/2017.

"TJ/PR - João Domingos Puppi, novo Desembargador" - Disponível em http://www.migalhas.com.br/Quentes/17,Ml46947,11049-

TJPR+Joao+Domingos+Puppi+novo+Desembargador; acesso em 29/04/2017.

"Vanessa Volpi Bellegard Palacios para Advogados pelo Impeachment" - Disponível em https://www.facebook.com/permalink.php?story fbid=240403276309145\&id=2403425429 81885; acesso 30/04/2017.

"Veja o perfil dos secretários de Beto Richa, com dois 'mourãoenses' entre eles, Douglas Fabrício e Ricardo Soavinski" - Disponível em http://www.crn1.com.br/noticias/36094/veja o perfil dos secretarios de beto richa co $\mathrm{m}$ dois mouraoenses entre eles douglas fabricio e ricardo soavinski.html; acesso em 29/04/2017.

"Vice de Greca será do PSB" - Disponível em http://www.esmaelmorais.com.br/2016/07/vice-degreca-sera-do-psb/; acesso em 27/04/2017. 